\title{
ANALISIS PERBANDINGAN METODE SINGLE EXPONENTIAL SMOOTHING DAN TREND PARABOLIK UNTUK PREDIKSI PENJUALAN KOPI (STUDI KASUS PADA TODAY COFFEE)
}

\author{
Dwi Bastomi, Karina Auliasari, Hani Zulfia Zahro' \\ Program Studi Teknik Informatika S1, Fakultas Teknologi Industri \\ Institut Teknologi Nasional Malang, Jalan Raya Karanglo km 2 Malang, Indonesia \\ 1718041@scholar.itn.ac.id
}

\begin{abstract}
ABSTRAK
Didalam dunia bisnis dan usaha mengharuskan perusahan untuk merancang berbagai macam strategi usaha untuk dapat bertahan. Peramalan atau prediksi inilah yang digunakan sebagai salah satu bahan pertimbangan terutama dalam sektor bisnis dan ekonomi, dimana kerugian suatu perusahaan dapat diminimalisir sebisa mungkin dan keuntungan dapat diraih semaksimal mungkin. Maka dari itu diperlukan suatu perhitungan untuk memprediksi setiap periodenya. Dalam hal ini diterapkan analisis perhitungan metode Trend Parabolic dan Single Exponential Smoothing dengan nilai alpha 0,1, 0,3, 0,5, 0,7 dan 0,9. Untuk menghitung prediksi penjualan kopi Today Coffee yang berada di Tulungagung. Kedua metode tersebut dibandingkan untuk mendapatkan nilai akurasi tertinggi (nilai kesalahan terkecil) dengan menggunakan perhitungan MAPE. Data yang digunakan sebagai prediksi adalah data penjualan kopi pada bulan juli 2020 sampai bulan maret 2021. Setelah dilakukan perhitungan didapatkan hasil prediksi menggunakan metode Trend Parabolic dengan nilai rata-rata $M A P E$ di semua varian rasa sebesar 37,23\% dan pada metode Single Exponential Smoothing mendapatkan nilai rata-rata $M A P E$ di semua varian rasa sebesar 54,37\%. Dengan demikian dapat disimpulkan bahwa metode Trend Parabolic lebih baik dalam memprediksi penjualan kopi di Today Coffee jika dibandingkan dengan metode Single Exponential Smoothing. Berdasarkan pengujian terhadap fitur-fitur pada aplikasi prediksi penjualan kopi pada Today Coffee seluruhnya dapat berjalan dengan baik.
\end{abstract}

Kata Kunci : Prediksi Penjualan, Single Exponential Smoothing, Trend Parabolic

\section{PENDAHULUAN}

Prediksi (forecasting) penjualan adalah proses menentukan perkiraan penjualan yang akan datang dalam bisnis selama periode waktu tertentu. Proses ini dapat dilakukan secara bulanan, triwulanan, atau bahkan tahunan, tergantung pada tujuan dan kebutuhan perusahaan. Perkiraan telah digunakan sebagai pertimbangan, terutama di bidang Bisnis dan Ekonomi, sehingga kerugian bisnis dapat diminimalisir dan keuntungan dapat dimaksimalkan. Dengan melakukan perkiraan, perusahaan dapat memprediksi jumlah penjualan pada periode berikutnya sesuai dengan hasil data penjualan sebelumnya.

Pada penelitian (Ulfa dkk, 2016) yang berjudul Perancangan Aplikasi Prediksi Jumlah Siswa Baru Pada Yayasan Cerdas Murni Menggunakan Exponential Smoothing, mampu memprediksikan jumlah siswa baru dengan metode Single Exponential Smoothing. Hasil uji perhitungan metode menggunakan data penerimaan siswa baru periode tahun 2011 - 2014, dapat disimpulkan bahwa Mean Square Error (MSE) terkecil diperoleh dengan nilai alpha 0.9 yaitu 3831,17 [1]. Dalam penelitian ini penulis akan membandingkan dua metode prediksi yaitu metode Trend Parabolic dengan metode Single Exponential Smoothing dalam menganalisa prediksi penjualan produk kopi. Pemilihan metode prediksi didasarkan pada tingkat kesalahan prediksi, dimana semakin kecil kesalahan yang dihasilkan, semakin tepat sebuah metode dalam memprediksi (Maricar, 2019). Perhitungan tingkat kesalahan yang digunakan berupa nilai MAPE, agar penelitian ini dapat terlaksana maka dipilihlah sebuah usaha sebagai subjek yaitu Today Coffee.

Kedai kopi ini terletak di Jln. Ahmad Yani Timur Gang 3 No.45, Bago, Kampungdalem, Kec. Tulungagung, Kabupaten Tulungagung, Jawa Timur. Kedai kopi ini memiliki beragam menu minuman antara lain Capucino, Cafelate, Coffe Signature, Red Velvet dan lain-lain. Berdasarkan wawancara kepada Pemilik Today Coffee selaku narasumber diketahui bahwa masalah yang dihadapi oleh pemilik adalah belum menerapkannya prediksi penjualan pada Today Coffee sehingga pemilik kesulitan dalam memprediksi penjualan produknya di bulan berikutnya. Metode yang digunakan dalam prediksi penjualan ini adalah metode Single Exponential Smoothing dan Trend Parabolic. Dan data yang digunakan sebagai bahan untuk penelitian adalah data penjualan kopi pada bulan juli 2020 sampai bulan maret 2021. Dengan kedua metode ini dalam memprediksi penjualan kopi dapat mengetahui mengalami kenaikan atau penurunan penjualan di bulan-bulan berikutnya dan untuk mengetahui implementasi kedua metode dalam prediksi serta membandingkan tingkat akurasi dari masing-masing metode. 


\section{TINJAUAN PUSTAKA}

\subsection{Penelitian Terdahulu}

Menurut penelitian Ulfa dkk yang berjudul "Perancangan Aplikasi Prediksi Jumlah Siswa Baru Pada Yayasan Cerdas Murni Menggunakan Exponential Smoothing". Penelitian ini bertujuan untuk membuat sebuah sistem pengkajian untuk memecahkan masalah yang di alami pada yayasan cerdas Murni, agar tidak mengalami kekeliruan dalam memprediksi jumlah siswa baru, yaitu dengan cara prediksi jumlah siswa baru dengan menggunakan metode Exponential Smoothing. Untuk melakukan prediksi peneliti membutuhkan data siswa baru pada periode 2011 sampai dengan data 2014. Hasil uji data dari hasil perhitungan yang telah dilakukan dapat disimpulkan bahwa Mean Square Error (MSE) terkecil diperoleh dengan alpha 0.9 yaitu 3831,17 . Hal ini menunjukkan bahwa forecast terbaik untuk meramalkan jumlah siswa baru diyayasan cerdas murni adalah dengan menggunakan alpha 0,9. Jadi, nilai prediksi jumlah siswa baru untuk tahun ajaran 2015-2016 dengan memprediksi selama dari data 2011 sampai dengan 2014 dengan alpha $=0.9$ adalah sebesar 333,41 atau sekitar 333 siswa [1].

Menurut penelitian Alfarisi Salman yang berjudul "Sistem Prediksi Penjualan Gamis Toko Qitaz Menggunakan Metode Single Exponential Smoothing". Penelitian ini bertujuan untuk membuat sebuah sistem yang dapat membantu dalam melakukan proses mengelola barang dan peramalan penjualan barang untuk periode berikutnya. Untuk melakukan prediksi peneliti membutuhkan data penjualan gamis toko qitaz bulan Januari - Desember 2016. Hasil uji data dari hasil perhitungannya berfluktuasi disekitar nilai mean (rata-rata) yang tetap tanpa trend dan pertumbuhan [2].

Menurut penelitian Siregar dkk yang berjudul "Perkiraan Penjualan Kopi Raja Di CV. Mahkota Jaya Abadi Padangsidimpuan Periode Januari 2017 Desember 2017". Penelitian ini bertujuan untuk memperkirakan penjualan kopi raja di CV. Mahkota Jaya Abadi Padangsidimpun periode Januari 2017 Desember 2017. Untuk melakukan prediksi peneliti membutuhkan data penjualan kopi raja CV. Mahkota Jaya Abadi Padangsidimpuan Januari 2016 Desember 2016. Peneliti menyimpulkan untuk metode yang lebih baik digunakan dalam penelitian ini adalah metode trend parabolik dengan persamaan $\mathrm{Y}=2.528,625+34,6 \mathrm{x}+15,42 \mathrm{x}^{2}$ persamaan ini memiliki MSE yang terkecil yaitu 161.632,1896 [3].

Menurut penelitian Fachrurrazi Sayed yang berjudul "Peramalan Penjualan Obat Menggunakan Metode Single Exponential Smoothing Pada Toko Obat Bintang Geurugok". Penelitian ini bertujuan untuk membuat suatu sistem informasi yang berbentuk program bantu yang dapat meramalankan pejualan obat berdasarkan riwayat penjualan sebelumnya. Dengan melihat penjualan sebelumnya, maka membantu pemilik dalam mengambil keputusan, untuk perlu tidaknya melakukan pembelian obat. Untuk melakukan prediksi peneliti membutuhkan data-data penjualan obat Ambeven dari Januari 2013 hingga Desember 2014. Pada tahap uji sampel didapat bahwa peramalan penjualan obat pada obat Ambeven bulan Maret 2015 berjumlah 49 tablet [4].

Menurut penelitian Kirana dkk yang berjudul "Analisis Metode Trend Parabolic untuk Proyeksi Indeks Pembangunan Manusia di Indonesia". Penelitian ini bertujuan untuk memproyeksikan tingkat perkembangan Indeks Pembangunan Manusia di Indonesia, agar pemerintah Indonesia memiliki referensi dan acuan yang jelas untuk menentukan kebijakan ataupun membuat langkah-langah strategis yang tepat agar Indeks Pembangunan Manusia di Indonesia jangan sampai menerun di masa yang akan datang, bahkan meningkat pada tiap tahunnya. Untuk melakukan penelitian ini peneliti membutuhkan data Indeks Pembangunan Manusia di Indonesia yang diperoleh dari BPS tahun 2010-2018. Hasil pengujian yang didapat setelah dilakukan pengujian secara Matematika dengan membandingkan data asli dengan data hasil proyeksi tidak terlalu jauh berbeda dengan MSE sebesar 0.017, dengan demikian metode proyeksi statistical parabolic (trend parabolic) baik digunakan untuk memproyeksi data Indeks Pembangunan Manusia di Indonesia untuk tahun 2019 dan tahun-tahun selanjutnya [5].

\subsection{Dasar Teori \\ 2.2.1 Forecasting}

Prediksi (Forecasting) merupakan gambaran keadaan perusahaan pada masa yang akan datang. Gambaran tersebut sangat penting bagi manajemen perusahaan karena dengan gambaran tersebut maka perusahaan dapat memprediksi langkah-langkah apa saja yang diambil dalam memenuhi permintaan konsumen. Ramalan memang tidak selalu tepat $100 \%$, karena masa depan mengandung masalah ketidakpastian, namun dengan pemilihan metode yang tepat dapat membuat peramalan dengan tingkat kesalahan yang kecil (Fachrurrazi, 2015).

\subsubsection{Metode Trend Parabolic}

Menurut Yudaruddin Rizky (2019), Trend parabolic atau dikenal dengan sebutan trend kuadrat adalah trend dengan variabel $\mathrm{X}$ berpangkat paling tinggi sehingga akan menghasilkan garis trend melengkung. Untuk mencari nilai prediksi dapat menggunakan rumus pada persamaan 2.1, persamaan 2.2, persamaan 2.3 dan persamaan 2.4

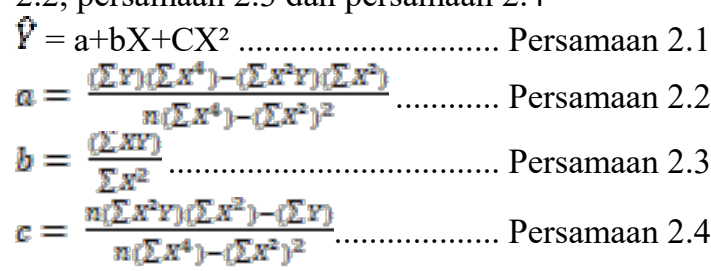

Keterangan :

$\hat{\eta} \quad=$ Hasil prediksi 
$\mathrm{X}=$ Periode waktu

$a, b, c=$ Konstanta

$n=$ Jumlah data

$\mathrm{Y} \quad=$ Nilai trend

Dalam hal ini dilakukan pembagian data menjadi dua kelompok, yaitu:

a. Data genap, maka nilai $x$ nya :

$$
\ldots-5,-3,-1,1,3,5 \ldots
$$

b. Data ganjil, maka nilai $x$ nya :

$$
\ldots-3,-2,-1,0,1,2,3 \ldots
$$

\subsubsection{Single Exponential Smoothing}

Metode Single Exponential Smoothing adalah metode yang menunjukan pembobotan menurun secara eksponensial terhadap nilai observasi yang lebih lama. Yaitu nilai yang lebih baru diberikan bobot yang relatif lebih besar dibanding nilai observasi yang lebih lama (Hartono dkk, 2015). Exponential Smoothing tergantung pada tiga bagian data: aktual terkini, perkiraan terbaru, dan konstanta smoothing. Nilai yang ditetapkan untuk $\alpha$ (konstanta smoothing) adalah kunci untuk perkiraan. Jika deret waktu tampak berubah dengan cukup lancar, maka perlu memberikan bobot lebih besar pada nilai aktual terkini. Di sisi lain, jika deret waktu cukup tidak menentu, maka perlu memberikan lebih sedikit bobot ke nilai aktual terkini yang diinginkan (Yudaruddin Rizky, 2019). Untuk mencari nilai prediksi dapat menggunakan rumus pada persamaan 2.5

$\mathrm{Ft}_{+1}=\alpha \mathrm{At}_{-1}+(1-\alpha) \mathrm{Ft}-$ Persamaan 2.5

Keterangan :

$\mathrm{Ft}_{+1}=$ peramalan untuk periode selanjutnya

$\mathrm{Ft}_{-1}=$ peramalan periode sebelumnya

$\alpha=$ konstanta smoothing $(0 \leq=\alpha<=1)$

At ${ }_{1}=$ nilai aktual periode sebelumnya

\subsubsection{MAPE}

Mean Absolute Percentage Error (MAPE) Merupakan perhitungan yang digunakan untuk menghitung rata-rata persentase kesalahan mutlak (Sukerti, N. K. 2015). Semakin rendah nilai MAPE, kemampuan dari model peramalan yang digunakan dapat dikatakan baik (Maricar, M. A., 2019). dan untuk MAPE terdapat range nilai yang dapat dijadikan bahan pengukuran mengenai kemampuan dari suatu model peramalan (Hutasuhut dkk, 2014). range nilai tersebut dapat dilihat pada tabel 1 .

Tabel 1. Karakteristik Nilai MAPE

\begin{tabular}{|l|l|}
\hline MAPE $(\%)$ & Interpretasi Akurasi Peramalan \\
\hline$<10$ & Sangat Baik \\
\hline $10-20$ & Baik \\
\hline $20-50$ & Cukup Baik \\
\hline$>50$ & Kurang \\
\hline
\end{tabular}

Untuk menghitung nilai MAPE dapat menggunakan rumus pada persamaan 2.6.
MAPE $=\frac{1}{n} \sum_{t=1}^{n} \frac{\llbracket Y_{L}-P_{L} \rrbracket}{Y_{t}} * 100 \% \ldots \ldots . .$. persamaan 2.6

Keterangan variabel:

$Y_{\mathrm{t}}=$ Nilai aktual pada periode $\mathrm{t}$

$\hat{Y}_{\mathrm{t}}=$ Nilai prediksi pada periode $\mathrm{t}$

$n=$ Jumlah data

\section{METODE PENELITIAN}

\subsection{Blok Diagram Sistem}

Blok diagram adalah diagram dari sebuah sistem, di mana bagian utama atau fungsi yang diwakili oleh blok dihubungkan dengan garis, yang menunjukkan hubungan dari blok. proses kerja pada prediksi penjualan kopi menggunakan metode Trend Parabolic dan Single Exponential Smoothing ditunjukan pada Gambar 1.

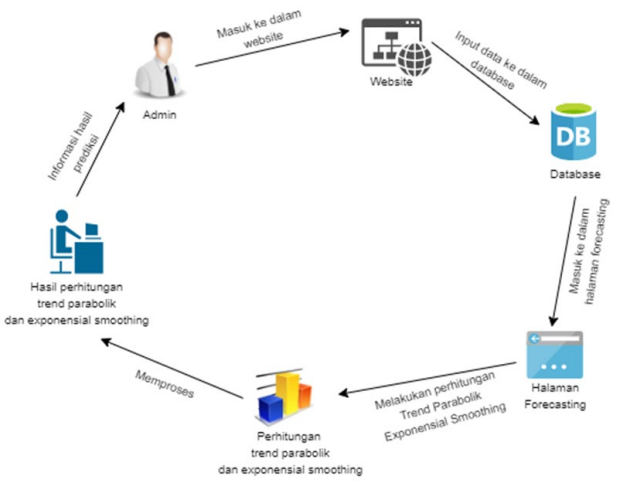

Gambar 1. Blok Diagram Sistem

\subsection{Flowchart Sistem}

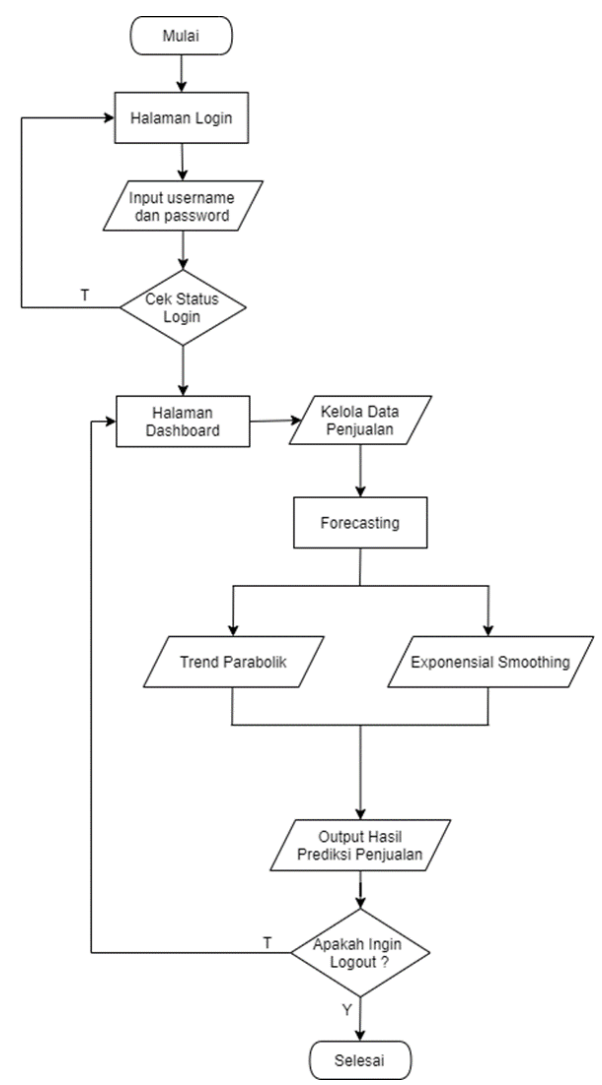

Gambar 2. Flowchart Sistem 
Flowchart sistem menggambarkan proses menjalankan aplikasi, seperti ditunjukkan pada Gambar 2.

Berdasarkan flowchart sistem pada Gambar 2, sistem dimulai dengan melakukan login dengan menginputkan username dan password, login akan dicek dahulu apakah username dan password yang diinputkan sudah benar. Jika benar maka admin akan masuk ke halaman menu dashboard, namum jika salah admin akan tetap di halaman login. Pada halaman menu dashboard, admin dapat melakukan kelola data penjualan dan dapat melakukan proses prediksi. Kemudian terdapat pilihan metode yaitu metode Trend Parabolic dan metode Single Exponential Smoothing dan apabila sudah memilih salah satu metode maka hasil prediksi penjualan akan tampil. Apabila proses yang dilakukan admin sudah selesai, admin dapat logout dan proses selesai.

\subsection{Flowchart Metode Trend Parabolic}

Flowchart metode ini menjelaskan proses urutan sistem dari metode Trend Paraobilc seperti ditunjukkan pada Gambar 3.

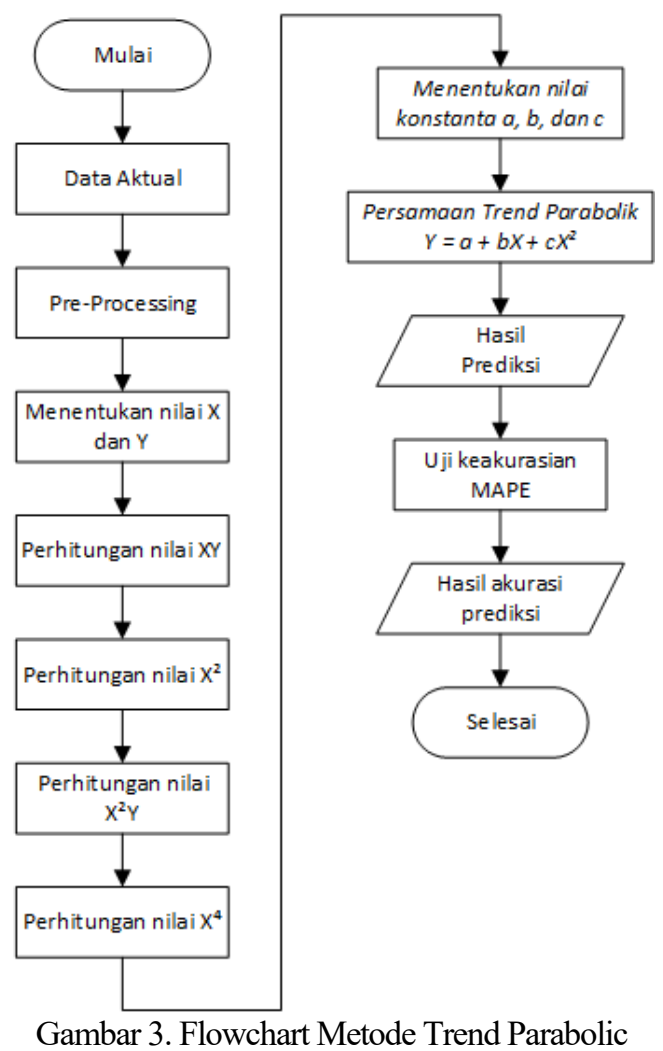

Berdasarkan flowchart pada Gambar 3, sistem dimulai dengan proses yang pertama kali pengumpulan data aktual yaitu data penjualan, dari data aktual ke proses pre-processing mengeleminasi variabel yang tidak dibutuhkan, selanjutnya menentukan nilai $X$, dimana $X$ merupakan variabel periode, dan $\mathrm{Y}$ merupakan banyaknya penjualan. ke proses selanjutnya perhitungan nilai $\mathrm{XY}$, nilai $\mathrm{X}^{2}$, nilai $X^{2} Y$, dan nilai $X^{4}$. kemudian menetukan nilai konstanta dari $\mathrm{a}, \mathrm{b}$, dan $\mathrm{c}$ sehingga didapat persamaan Trend Parabolic. Dari nilai Y yang didapat dilakukan uji keakurasian dengan menggunakan MAPE (Mean Absolute Percentage Error) untuk mengetahui presentase error.

\subsection{Flowchart Metode Single Exponential Smoothing}

Flowchart metode ini menjelaskan proses urutan sistem dari metode Single Exponential Smoothing seperti ditunjukkan pada Gambar 4.

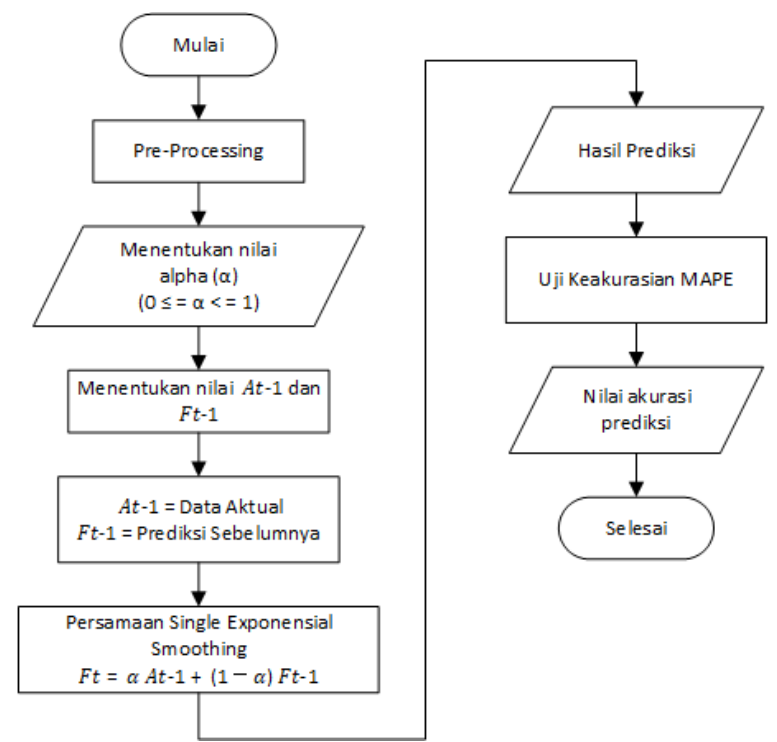

Gambar 4. Flowchart Metode Single Exponential Smoothing

Berdasarkan flowchart pada Gambar 4, sistem dimulai dengan proses yang pertama kali Preprocessing mengeleminasi variabel yang tidak dibutuhkan, selanjutnya menentukan nilai alpha, untuk besaran nilai alpha yaitu 0,1-0,9. Kemudian mencari nilai At-1 dan Ft-1, dimana At-1 merupakan data aktual dan $\mathrm{Ft}_{-1}$ merupakan data prediksi sebelumnya, selanjutnya menghitung prediksi data penjualan yang akan datang dengan rumus $F t=\alpha$ $A t-1+(1-\alpha) F t-1$. Dari nilai Ft yang didapat dilakukan uji keakurasian dengan menggunakan MAPE (Mean Absolute Percentage Error) untuk mengetahui presentase error.

\section{HASIL DAN PEMBAHASAN}

\subsection{Halaman Login}

Pada halaman login diberikan hak akses admin untuk login. Admin harus memasukkan username dan password untuk dapat masuk ke halaman utama admin. Tampilan halaman login dapat ditunjukkan pada Gambar 5. 


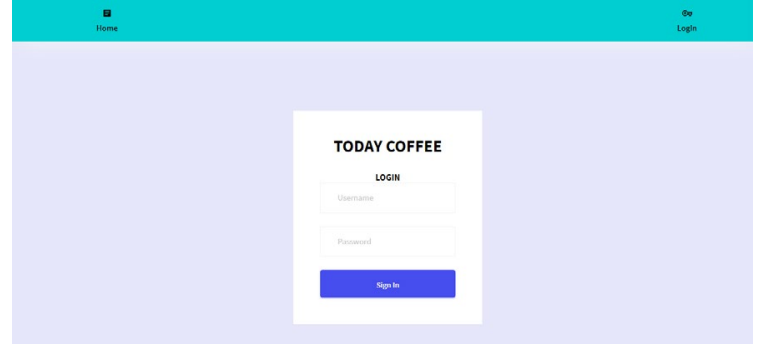

Gambar 5. Halaman Login

\subsection{Halaman Dashboard}

Pada halaman dashboard terdapat menu topbar untuk masuk ke halaman data produk, data penjualan produk, dan prediksi. Dan halaman admin adalah halaman yang pertama kali diakses oleh admin. Tampilan halaman admin dapat ditunjukkan pada gambar Gambar 6.

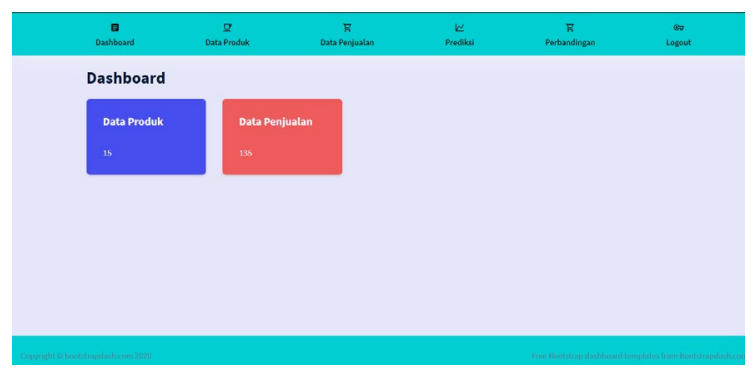

Gambar 6. Halaman Dashboard

\subsection{Halaman Data Produk}

Pada tampilan halaman data produk terdapat data varian rasa dan harga produk dengan demikian admin dapat melihat, menambahkan, mengubah, menghapus data produk. Tampilan halaman data produk dapat ditunjukkan pada gambar 7.

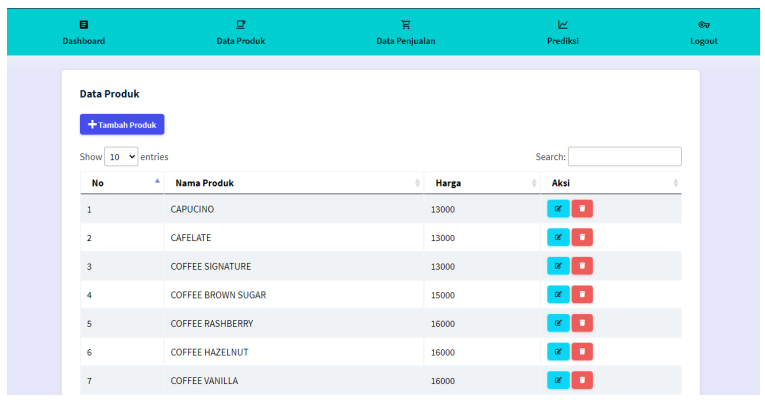

Gambar 7. Halaman Data Produk

\subsection{Halaman Data Penjualan}

Pada tampilan halaman data penjualan terdapat data varian rasa, periode dan jumlah penjualan dengan demikian admin dapat melihat, menambahkan, mengubah, menghapus data penjualan. Tampilan halaman data penjualan dapat ditunjukkan pada gambar 8

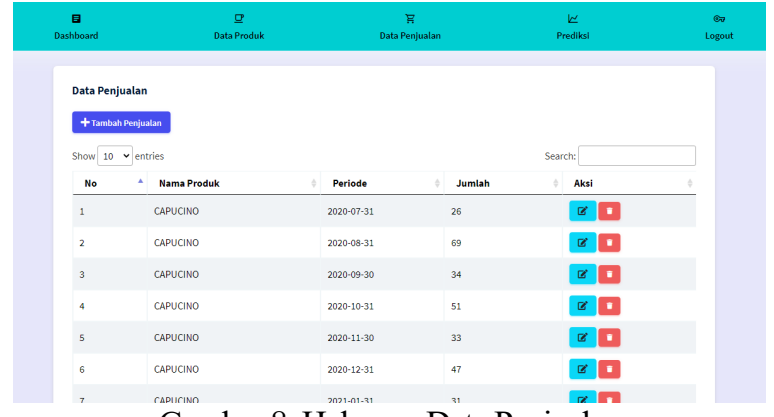

Gambar 8. Halaman Data Penjualan

\subsection{Halaman Prediksi Trend Parabolic}

Pada tampilan halaman prediksi trend parabolik, admin dapat memprediksi penjualan dengan memasukkan periode dan memilih tombol hitung akan menampilkan perhitungan metode Trend Parabolic dan grafik. Tampilan halaman prediksi Trend Parabolic dapat ditunjukkan gambar 9.

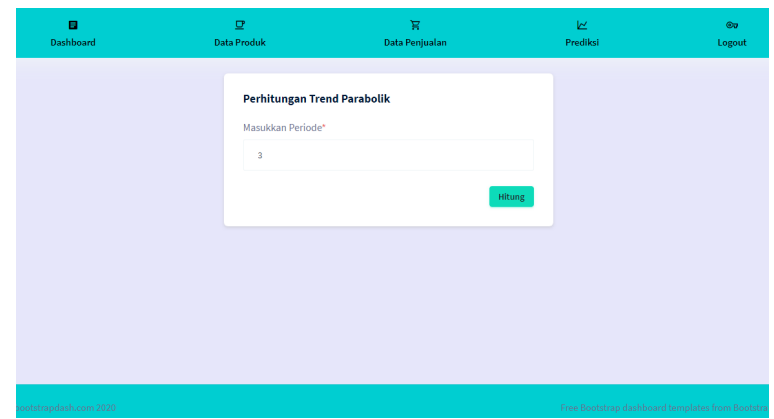

Gambar 9. Halaman Prediksi Trend Parabolik

4.6. Halaman Prediksi Single Exponential Smoothing

Pada tampilan halaman prediksi SES, admin dapat memprediksi penjualan dengan memasukkan nilai alpha, periode, dan memilih tombol hitung akan menampilkan perhitungan metode SES dan grafik. Tampilan halaman prediksi $S E S$ dapat ditunjukkan gambar 10.

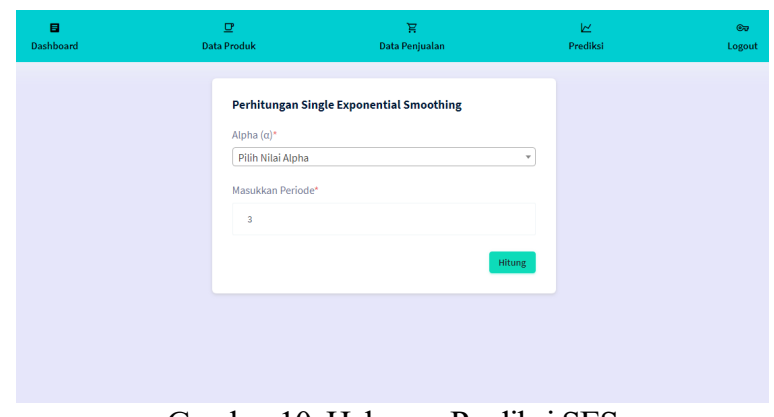

Gambar 10. Halaman Prediksi SES

\subsection{Perhitungan Metode Trend Parabolic}

Dalam perhitungan Metode Trend Parabolic penulis mengambil data pada bulan Juni 2020 - Maret 2021 pada kedai kopi Today Coffee di Tulungagung. Data yang diambil adalah data penjualan pada kedai kopi Today Coffee. 


\subsection{Varian rasa Chocholate}

Pada tabel 2 perhitungan prediksi dengan metode Trend Parabolic untuk varian rasa chocholate dengan nilai Y banyaknya penjualan varian rasa chocholate dan nilai X merupakan kolom periode. Kolom XY merupakan hasil perkalian dari kolom $\mathrm{X}$ dan kolom $\mathrm{Y}$ dan kolom $\mathrm{X}^{2}$ merupakan hasil kuadrat dari kolom X. Setelah didapat nilai $Y, X, X Y, X^{2}, X^{2} Y, X^{4}$ selanjutnya mencari nilai $a, b$, dan $\mathrm{c}$ untuk membentuk persamaan trend parabolik. Dari perhitungan menggunakan rumus pada persamaan 2.2, persamaan 2.3 dan persamaan 2.4 didapat persamaan trend parabolik $Y^{\wedge}=43,45+-4,23 X+-0,32 X^{2}$.

Untuk mengetahui keakurasian dari hasil prediksi penjualan dapat dilakukan menggunakan MAPE. Semakin kecil penyimpangan antara data aktual dengan data prediksi maka metode prediksi yang digunakan baik. Dari perhitungan akurasi diperoleh nilai $12,75 \%$. Hasil ini menujukan prediksi penjualan varian rasa Chocholate menggunakan Trend Parabolic baik.

Tabel 2. Perhitungan Varian rasa Chocholate

\begin{tabular}{|l|l|l|l|l|l|l|l|}
\hline Periode & $\mathrm{Y}$ & $\mathrm{X}$ & $\mathrm{XY}$ & $\mathrm{X}^{2}$ & $\mathrm{X}^{2} \mathrm{Y}$ & $\mathrm{X}^{4}$ & Prediksi \\
\hline Jul-20 & 47 & -4 & -188 & 16 & 752 & 256 & 55,30 \\
\hline Agu-20 & 65 & -3 & -195 & 9 & 585 & 81 & 53,29 \\
\hline Sep-20 & 49 & -2 & -98 & 4 & 196 & 16 & 50,65 \\
\hline Okt-20 & 47 & -1 & -47 & 1 & 47 & 1 & 47,37 \\
\hline Nov-20 & 49 & 0 & 0 & 0 & 0 & 0 & 43,45 \\
\hline Des-20 & 34 & 1 & 34 & 1 & 34 & 1 & 38,90 \\
\hline Jan-21 & 30 & 2 & 60 & 4 & 120 & 16 & 33,72 \\
\hline Feb-21 & 24 & 3 & 72 & 9 & 216 & 81 & 27,89 \\
\hline Mar-21 & 27 & 4 & 108 & 16 & 432 & 256 & 21,43 \\
\hline Total & 372 & 0 & -254 & 60 & 2382 & 708 & 372 \\
\hline
\end{tabular}

Menentukan nilai $a, b$ dan $c$

$$
\begin{aligned}
& a=\frac{\left(\sum Y\right)\left(\sum x^{4}\right)-\left(\sum x^{2} Y\right)\left(\Sigma X^{2}\right)}{n\left(\Sigma X^{4}\right)-\left(\sum x^{2}\right)^{2}}=\frac{(972)(708)-(2382)(60)}{9(708)-(60)^{2}} \\
& =\frac{120456}{2772}=43,45 \\
& b=\frac{\left[\sum X Y 2\right)}{\left(\sum x^{2}\right)}=\frac{(-254)}{(60)}=-4,23 \\
& c=\frac{n\left(\Sigma x^{2} Y\right)-\left(\sum x^{2}\right)(\Sigma Y)}{n\left(\Sigma x^{4}\right)-\left(\sum x^{2}\right)^{2}}=\frac{9(2392)-(60)(272)}{9(708)-(60)^{2}} \\
& =\frac{-892}{2772}=-0,32
\end{aligned}
$$

Pada gambar 11 terdapat grafik dari nilai data aktual yang berwarna garis biru penjualan varian rasa chocholate dan nilai prediksi berwarna garis hitam. Perbedaan keduanya yang tidak terlalu jauh untuk dijadikan indikasi jika prediksi menggunakan metode Trend Parabolic akurat.

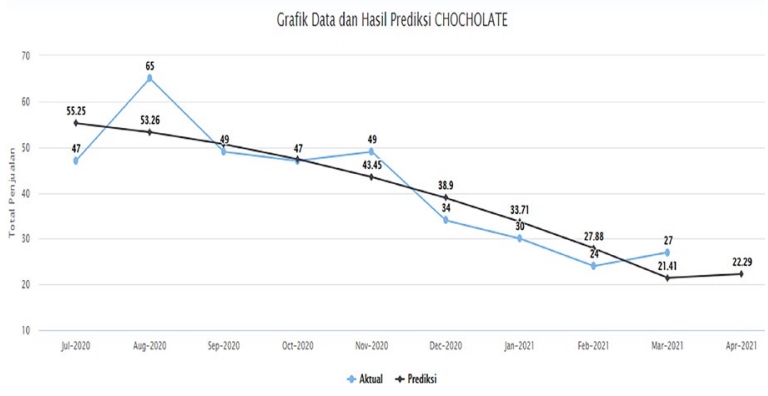

Gambar 11. grafik varian rasa chocholate

\subsection{Perhitungan Metode Single Exponential Smoothing}

Dalam perhitungan Metode Single Exponential Smoothing penulis mengambil data pada bulan Juni 2020 - Maret 2021 pada kedai kopi Today Coffee di Tulungagung. Data yang diambil adalah data penjualan pada kedai kopi Today Coffee. Dalam memprediksi jumlah data penjualan pada kedai kopi Today Coffee diperlukan kriteria-kriteria dan bobot untuk melakukan perhitungannya sehingga akan didapatkan hasil yang terbaik. Dalam prediksi ini, nilai alpha $(\alpha)$ yang akan dicoba (trial) secara acak sebagai nilai bobot $(\alpha=0.1),(\alpha=0.3),(\alpha=0.5),(\alpha=$ $0.7)$, dan $(\alpha=0.9)$.

\subsection{Varian rasa Chocholate}

Pada tabel 3 data penjualan untuk varian rasa chocholate, Dalam perhitungan prediksi ini, nilai bobot $(\alpha)$ yang akan dicoba (trial) secara acak sebagai nilai bobot $(\alpha$ $=0.1),(\alpha=0.3),(\alpha=0.5),(\alpha=0.7)$, dan $(\alpha=0.9)$. Untuk mengetahui keakurasian dari hasil prediksi penjualan dapat dilakukan menggunakan MAPE. Semakin kecil penyimpangan antara data aktual dengan data prediksi maka metode prediksi yang digunakan baik. Dari perhitungan akurasi diperoleh nilai $(\alpha=0,1)$ sebesar $35,41 \%,(\alpha=0,3)$ sebesar 30,38\%, $(\alpha=0,5)$ sebesar 24,95\%, $(\alpha=0,7)$ sebesar $21,30 \%,(\alpha=0,9)$ sebesar $20,65 \%$. Hasil ini menujukan prediksi penjualan varian rasa chocholate menggunakan Single Exponential Smoothing cukup baik dengan nilai $\alpha=0,9$.

Tabel 3. penjualan varian rasa chocholate

\begin{tabular}{|c|c|}
\hline Periode & Penjualan (cups) \\
\hline Jul-20 & 47 \\
\hline Agu-20 & 65 \\
\hline Sep-20 & 49 \\
\hline Okt-20 & 47 \\
\hline Nov-20 & 49 \\
\hline Des-20 & 34 \\
\hline Jan-21 & 30 \\
\hline Feb-21 & 24 \\
\hline Mar-21 & 27 \\
\hline
\end{tabular}

Berikut perhitungan untuk konstanta alpha $(\alpha=0,9)$

1. Data penjualan pertama pada periode Jul-20 sebesar 47. Untuk periode selanjutnya belum bisa membuat forecast. Untuk membuat forecast periode Agu-20 juga belum mempunyai cukup data. Untuk itu, boleh ditentukan secara bebas, asal kira-kira mendekati. Sehingga untuk forecast periode Agu-20 $\left(\mathrm{F}_{2}\right)$ sebesar 47, sama dengan nilai penjualan pada periode Jul-20.

2. Untuk periode Sep-20 perhitungannya sebagai berikut:

$$
\begin{aligned}
\mathrm{F}_{3} & =\alpha^{*} \mathrm{At}_{-1}+(1-\alpha)^{*} \mathrm{Ft}_{-1} \\
& =0,1 *(65)+(1-0,1) * 47=63,2
\end{aligned}
$$

3. Untuk periode Okt-20 perhitungannya sebagai berikut:

$$
\begin{aligned}
\mathrm{F}_{4} & =\alpha^{*} \mathrm{At}_{-1}+(1-\alpha)^{*} \mathrm{Ft}_{-1} \\
& =0,1 *(49)+(1-0,1) * 63,2=50,42
\end{aligned}
$$


4. Untuk periode Nov-20 perhitungannya sebagai berikut:

$$
\begin{aligned}
\mathrm{F}_{5} & =\alpha^{*} \mathrm{At}_{-1}+(1-\alpha)^{*} \mathrm{Ft}_{-1} \\
& =0,1 *(47)+(1-0,1) * 50,42=47,342
\end{aligned}
$$

Dan seterusnya hingga periode Mar-21.

\subsection{Uji Akurasi Trend Parabolik}

Setelah melakukan prediksi terhadap semua jenis varian rasa yang ada di Today Coffee, pengujian keakurasian dilakukan untuk memastikan tingkat akurasi dari hasil perhitungan prediksi hasil penjualan kopi menggunakan metode Trend Parabolik pada Today Coffee di Tulungagung. Pegujian keakurasian menggunakan $M A P E$. Tabel pengujian keakurasian seperti ditunjukkan pada tabel 4.

Tabel 4. Uji akurasi Trend Parabolic

\begin{tabular}{|l|c|}
\hline \multicolumn{1}{|c|}{ Varian Rasa } & $\begin{array}{c}\text { Ukuran } \\
\text { Evaluasi } \\
\text { MAPE }\end{array}$ \\
\hline Capucino & $29,24 \%$ \\
\hline Coffee Signature & $29,55 \%$ \\
\hline Coffee Brown Sugar & $25,63 \%$ \\
\hline Coffee Rum & $25,98 \%$ \\
\hline Red Velvet & $23,01 \%$ \\
\hline Chocholate & $12,75 \%$ \\
\hline Tiramisu & $14,17 \%$ \\
\hline
\end{tabular}

\subsection{Uji Akurasi Single Exponential Smoothing}

Setelah melakukan prediksi terhadap semua jenis varian rasa yang ada di Today Coffee, pengujian keakurasian dilakukan untuk memastikan tingkat akurasi dari hasil perhitungan prediksi hasil penjualan kopi menggunakan metode Single Exponential Smoothing pada Today Coffee di Tulungagung. Pegujian keakurasian menggunakan $M A P E$. Tabel pengujian keakurasian seperti ditunjukkan pada tabel 5.

Tabel 5. Uji akurasi Single Exponential Smoothing

\begin{tabular}{|l|c|c|c|c|c|}
\hline Varian rasa & 0,1 & 0,3 & 0,5 & 0,7 & 0,9 \\
\hline Capucino & $48,83 \%$ & $36,00 \%$ & $38,02 \%$ & $42,84 \%$ & $48,83 \%$ \\
\hline $\begin{array}{l}\text { Coffee } \\
\text { Signature }\end{array}$ & $49,76 \%$ & $60,32 \%$ & $54,69 \%$ & $51,95 \%$ & $49,76 \%$ \\
\hline $\begin{array}{l}\text { Coffee } \\
\text { Brown } \\
\text { Sugar }\end{array}$ & $43,91 \%$ & $48,65 \%$ & $46,36 \%$ & $44,32 \%$ & $43,91 \%$ \\
\hline $\begin{array}{l}\text { Coffee } \\
\text { Rum }\end{array}$ & $38,20 \%$ & $48,28 \%$ & $39,98 \%$ & $37,95 \%$ & $38,20 \%$ \\
\hline Red Velvet & $50,94 \%$ & $79,10 \%$ & $59,84 \%$ & $50,57 \%$ & $50,94 \%$ \\
\hline Chocholate & $20,65 \%$ & $30,38 \%$ & $24,95 \%$ & $21,30 \%$ & $20,65 \%$ \\
\hline Tiramisu & $30,01 \%$ & $42,51 \%$ & $36,80 \%$ & $32,93 \%$ & $30,01 \%$ \\
\hline
\end{tabular}

\subsection{Analisis Perbandingan Metode Single} Exponential Smoothing dengan Trend Parabolic

Penulis akan membandingkan metode Single Exponential Smoothing dan metode Trend Parabolic untuk 15 varian rasa dengan ketentuan nilai alpha adalah yang terbaik (memiliki nilai MAPE terkecil), data yang digunakan adalah data penjualan Today Coffee periode bulan Juli 2020 sampai bulan Maret 2021. Hasil dari pengujian perbandingan kedua metode dapat ditujukkan pada Tabel 6 .
Tabel 6. Hasil Perbandingan Nilai MAPE Terkecil

\begin{tabular}{|l|l|c|c|c|}
\hline No & \multicolumn{1}{|c|}{ Varian rasa } & $\begin{array}{c}\text { Nilai } \\
\text { Alpha }\end{array}$ & $\begin{array}{c}\text { MAPE } \\
\text { SES }\end{array}$ & $\begin{array}{c}\text { MAPE } \\
\text { TP }\end{array}$ \\
\hline 1 & Capucino & 0,1 & $29,96 \%$ & $29,24 \%$ \\
\hline 2 & Cafelate & 0,1 & $32,75 \%$ & $47,27 \%$ \\
\hline 3 & Coffee Signature & 0,9 & $49,76 \%$ & $29,55 \%$ \\
\hline 4 & $\begin{array}{l}\text { Coffee Brown } \\
\text { Sugar }\end{array}$ & 0,9 & $43,91 \%$ & $25,63 \%$ \\
\hline 5 & Coffee Rashberry & 0,7 & $126,92 \%$ & $69,31 \%$ \\
\hline 7 & Coffee Hazelnut & 0,1 & $64,60 \%$ & $43,72 \%$ \\
\hline 8 & Coffee Rum & 0,9 & $80,44 \%$ & $46,07 \%$ \\
\hline 9 & Coffee Banana & 0,7 & $37,95 \%$ & $25,98 \%$ \\
\hline 10 & Coffee Caramel & 0,9 & $56,72 \%$ & $41,91 \%$ \\
\hline 11 & Taro & 0,1 & $31,82 \%$ & $77,68 \%$ \\
\hline 12 & Greentea & 0,7 & $42,83 \%$ & $39,93 \%$ \\
\hline 13 & Red Velvet & 0,7 & $50,57 \%$ & $23,01 \%$ \\
\hline 14 & Chocholate & 0,9 & $20,65 \%$ & $12,75 \%$ \\
\hline 15 & Tiramisu & 0,9 & $30,01 \%$ & $14,17 \%$ \\
\hline \multicolumn{2}{|c|}{ Rata-rata } & & $54,37 \%$ & $37,23 \%$ \\
\hline
\end{tabular}

Keterangan:

SES: Single Exponential Smoothing

TP: Trend Parabolic

Berdasarkan tabel 6, dapat diambil kesimpulan bahwa metode Trend Parabolic dengan data penjualan Today Coffee periode bulan Juli 2020 sampai bulan Maret 2021 menghasilkan nilai rata-rata MAPE terkecil di semua varian rasa sebesar 37,23\% jika dibandingkan dengan metode Single Exponential Smoothing sebesar 54,37\%.

\subsection{Pengujian Fungsionalitas}

Pada pengujian Fungsionalitas sistem akan dilakukan percobaan untuk menguji semua fungsi yang yang ada pada sistem apakah bekerja dengan normal atau tidak. Pengujian dilakukan pada 3 browser pada perangkat dengan spesifikasi CPU yang digunakan adalah Intel(R) Core(TM) i7-7500U Processor (4MB Cache, up to 3.50 $\mathrm{GHz}$ ), RAM 8 GB. Hasil dari pengujian fungsionalitas sistem dapat ditujukkan pada Tabel 7.

\begin{tabular}{|c|c|c|c|}
\hline \multirow[b]{2}{*}{ Fungsi } & \multicolumn{3}{|c|}{ Browser } \\
\hline & $\begin{array}{c}\text { Microsoft } \\
\text { Edge }\end{array}$ & $\begin{array}{l}\text { Google } \\
\text { Chrome }\end{array}$ & $\begin{array}{l}\text { Mozilla } \\
\text { Firefox }\end{array}$ \\
\hline Login & $\sqrt{ }$ & $\sqrt{ }$ & $\sqrt{ }$ \\
\hline $\begin{array}{l}\text { Halaman } \\
\text { Dashboard }\end{array}$ & $\sqrt{ }$ & $\sqrt{ }$ & $\sqrt{ }$ \\
\hline Data Produk & $\sqrt{ }$ & $\sqrt{ }$ & $\sqrt{ }$ \\
\hline $\begin{array}{l}\text { Tambah Data } \\
\text { Produk }\end{array}$ & $\sqrt{ }$ & $\sqrt{ }$ & $\sqrt{ }$ \\
\hline Ubah Data Produk & $\sqrt{ }$ & $\sqrt{ }$ & $\sqrt{ }$ \\
\hline Hapus Data Produk & $\sqrt{ }$ & $\sqrt{ }$ & $\sqrt{ }$ \\
\hline Data Penjualan & $\sqrt{ }$ & $\sqrt{ }$ & $\sqrt{ }$ \\
\hline $\begin{array}{ll}\text { Tambah } \\
\text { Penjualan }\end{array}$ & $\sqrt{ }$ & $\sqrt{ }$ & $\sqrt{ }$ \\
\hline $\begin{array}{ll}\text { Ubah } & \text { Data } \\
\text { Penjualan } & \end{array}$ & $\sqrt{ }$ & $\sqrt{ }$ & $\sqrt{ }$ \\
\hline $\begin{array}{ll}\begin{array}{l}\text { Hapus } \\
\text { Penjualan }\end{array} & \text { Data } \\
\end{array}$ & $\sqrt{ }$ & $\sqrt{ }$ & $\sqrt{ }$ \\
\hline Forecasting & $\sqrt{ }$ & $\sqrt{ }$ & $\sqrt{ }$ \\
\hline Perhitungan & $\sqrt{ }$ & $\sqrt{ }$ & $\sqrt{ }$ \\
\hline Grafik & $\sqrt{ }$ & $\sqrt{ }$ & $\sqrt{ }$ \\
\hline $\begin{array}{l}\text { Perbandingan } \\
\text { Metode }\end{array}$ & $\sqrt{ }$ & $\sqrt{ }$ & $\sqrt{ }$ \\
\hline Logout & $\sqrt{ }$ & $\sqrt{ }$ & $\sqrt{ }$ \\
\hline
\end{tabular}

Tabel 7. Pengujian Fungsionalitas Sistem 
Keterangan:

$\sqrt{ }=$ Berjalan

$\mathrm{x}=$ Tidak berjalan

Berdasarkan Tabel 7 diketahui bahwa seluruh fungsi pada aplikasi forecasting yang dikembangkan dapat berjalan pada Microsoft Edge, Google Chrome dan Mozilla Firefox. Oleh karena itu, aplikasi forecasting dapat dijalankan dengan baik pada browser web.

\section{KESIMPULAN DAN SARAN}

\subsection{Kesimpulan}

Kesimpulan yang dapat penulis paparkan setelah melakukan peracangan prediksi penjualan kopi antara lain yaitu:

1. Berdasarkan hasil analisis prediksi dengan menggunakan metode Trend Parabolic pada semua varian rasa nilai rata-rata $M A P E$ sebesar $37,23 \%$ lebih kecil dari hasil prediksi dengan menggunakan metode Single Exponential Smoothing yang didapat nilai rata-rata $M A P E$ sebesar $54,37 \%$.

2. Penggunaan nilai bobot $(\alpha)$ untuk metode Single Exponential Smoothing setiap varian rasa pada Today Coffee berbeda-beda.

3. Berdasarkan hasil pengujian fungsionalitas pada aplikasi forecasting penjualan kopi dapat dijalankan dengan baik pada browser web.

\subsection{Saran}

Berdasarkan penelitian yang telah dilakukan, maka penulis dapat memberikan beberapa saran-saran untuk pengembangan selanjutnya antara lain :

1. Penelitian selanjutnya bisa memprediksi dengan menggunakan metode forecasting lainnya antara lain Linear Regression, Moving Avarage, dan Trend Moment.

2. Penelitian selanjutnya pengembangan sistem dapat menambahkan fitur untuk transaksi penjualan.

\section{DAFTAR PUSTAKA}

[1] Ulfa, K. N., \& Syahrizal, M. (2016). Perancangan Aplikasi Prediksi Jumlah Siswa Baru pada Yayasan Cerdas Murni Menggunakan Exponential Smoothing. JURIKOM (Jurnal Riset Komputer), 3(6).

[2] Alfarisi, S. (2017). Sistem Prediksi Penjualan Gamis Toko QITAZ Menggunakan Metode Single Exponential Smoothing. JABE (Journal of Applied Business and Economic), 4(1), 80-95.

[3] Siregar, A. I. A., Cahyani, U. E., \& Siregar, A. I. A. (2017). Perkiraan penjualan kopi raja di
CV. Mahkota Jaya Abadi Padangsidimpuan periode Januari 2017-Desember 2017 (Doctoral dissertation, IAIN Padangsidimpuan)

[4] Fachrurrazi, S. (2019). Peramalan Penjualan Obat Menggunakan Metode Single Exponential Smoothing Pada Toko Obat Bintang Geurugok. TECHSI-Jurnal Teknik Informatika, 7(1), 19-30.

[5] Kirana, I. O., Nasution, Z. M., \& Wanto, A. (2019, August). Analisis Metode Trend Parabolic untuk Proyeksi Indeks Pembangunan Manusia di Indonesia. In Seminar Nasional Aplikasi Teknologi Informasi (SNATI).

[6] Fachrurrazi, S. (2019). Peramalan Penjualan Obat Menggunakan Metode Single Exponential Smoothing Pada Toko Obat Bintang Geurugok. TECHSI-Jurnal Teknik Informatika, 7(1), 19-30.

[7] Handoko, W. (2019). Prediksi Jumlah Penerimaan Mahasiswa Baru Dengan Metode Single Exponential Smoothing (Studi Kasus: Amik Royal Kisaran). JURTEKSI (Jurnal Teknologi dan Sistem Informasi), 5(2), 125-132.

[8] Hutasuhut, A. H., Anggraeni, W., \& Tyasnurita, R. (2014). Pembuatan Aplikasi Pendukung Keputusan untuk Peramalan Persediaan Bahan Baku Produksi Plastik Blowing dan Inject Menggunakan Metode ARIMA (Autoregressive Integrated Moving Average) di CV. Asia. Jurnal Teknik ITS, 3(2), A169-A174.

[9] Maricar, M. A. (2019). Analisa Perbandingan Nilai Akurasi Moving Average dan Exponential Smoothing untuk Sistem Peramalan Pendapatan pada Perusahaan XYZ. Jurnal Sistem dan Informatika (JSI), 13(2), 36-45.

[10] Margi S, K., \& Pendawa W, S. (2015). Analisa Penerapan Metode Single Exponential Smoothing Untuk Prediksi Penjualan Pada Periode Tertentu (Studi Kasus : PT. Media Cemara Kreasi). Prosiding SNATIF, pp. 259266.

[11] Hartono, A., Dwijana, D., \& Handiwidjojo, W. (2015). PERBANDINGAN METODE SINGLE EXPONENTIAL SMOOTHING DAN METODE EXPONENTIAL SMOOTHING ADJUSTED FOR TREND (HOLT'S METHOD) UNTUK MERAMALKAN PENJUALAN. STUDI KASUS: TOKO ONDERDIL MOBIL "PRODI, PURWODADI". Jurnal Eksplorasi Karya Sistem Informasi dan Sains, 5(1). 